\title{
Sektion A
}

Forum $2019 \cdot 34: 300$

https://doi.org/10.1007/s12312-019-0629-y

Online publiziert: 7. Mai 2019

C) Springer Medizin Verlag $\mathrm{GmbH}$, ein Teil von

Springer Nature 2019

\section{bremer \\ krebsgesellschaft}

\section{Ankündigung Bremer Krebskongress 2019 \\ Kommunikation in der Onkologie - von Zelle zu Zelle, von Mensch zu Mensch}

Kommunikation in der Onkologie - das Programm des 16. Bremer Krebskongress am 12. und 13. November im swissôtel steht und die Ankündigungsplakate sind frisch gedruckt. Wir freuen uns sehr, dass ZDF-Moderatorin Kay-Sölve Richter den Eröffnungsvortrag hält und das Leitthema des Kongresses „Kommunikation in der Onkologie - von Zelle zu Zelle, von Mensch zu Mensch" aus journalistischem Blickwinkel betrachten wird: Wie kommt eine Nachricht in die Nachrichten? Das ist eine interessante Frage angesichts des Medienrummels um „bahnbrechende“ Fortschritte in der Krebsmedizn: Wir erinnern uns noch an die intensiven Diskussionen um den Einsatz von Methadon in der Krebstherapie.
In den wissenschaftlichen Beiträgen und dem Schülerforum wird es um die Übermittlung von guten und schlechten Nachrichten an Patienten, um den Informationsaustausch von Ärztinnen und Ärzten untereinander, aber auch um die Kommunikation von Zellen bei Tumorerkrankungen gehen. Mit den beiden Kongresspräsidenten Prof. Christiane Franzius und Prof. Jörn Bullerdiek freuen wir uns auf den bevorstehenden Kongress und auf Ihren Besuch.

\section{Korrespondenzadresse}

\section{Marie Rösler}

Bremer Krebsgesellschaft e.V.

Am Schwarzen Meer 101, 28205 Bremen, Deutschland roesler@bremerkrebsgesellschaft.de

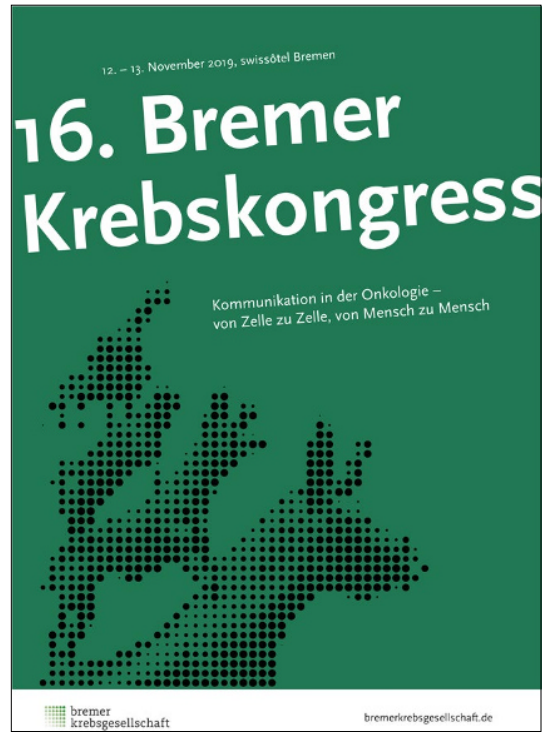

